\title{
Aplicação do Método Mesmis para Análise da Sustentabilidade de Sistemas de Produção da Pecuária Familiar em Área do Bioma Pampa no Rio Grande do Sul
}

\author{
http://dx.doi.org/10.21527/2237-6453.2018.45.354-376 \\ Recebido em: $27 / 2 / 2017$ \\ Aceito em: 20/5/2018 \\ Carolina da Silveira Nicoloso ${ }^{1}$, Vicente Celestino Pires Silveira ${ }^{2}$ \\ Roblein Cristal Coelho Filho ${ }^{3}$, Fernando Luiz Ferreira de Quadros ${ }^{4}$
}

\begin{abstract}
RESUMO
Por representar um conjunto de ecossistemas muito antigos, o Bioma Pampa apresenta flora e fauna próprias e grande biodiversidade, ainda não completamente descrita pela ciência. Desde a colonização ibérica, a pecuária extensiva (bovinos de corte e ovinos) sobre os campos nativos tem sido a principal atividade econômica da região. A progressiva introdução e expansão das monoculturas e das pastagens com espécies exóticas tem levado a uma rápida degradação e descaracterização das paisagens naturais do Pampa. O objetivo deste artigo é avaliar a sustentabilidade de diferentes sistemas de produção da pecuária familiar no Rio Grande do Sul. Foi utilizado o método Mesmis para a análise de sustentabilidade de três grupos de sistemas de produção identificados: Campo Nativo (CN), Campo Nativo e Cultivos (CN+C) e Campo Nativo e Soja (CN+S). Foi identificada diferença significativa $(p<0,05)$ para o atributo "Produtividade" entre os sistemas $\mathrm{CN}+\mathrm{C}$ e $\mathrm{CN}+\mathrm{S}$, com o primeiro mostrando-se superior ao segundo. Para os demais atributos de sustentabilidade não houve diferenças significativas entre os sistemas de produção da pecuária familiar estudados.
\end{abstract}

Palavras-chave: Sustentabilidade. Pecuária familiar. Soja.

\section{METHOD MESMIS APPLICATION FOR ANALYSIS OF SUSTAINABILITY OF FAMILIAR LIVESTOCK PRODUCTION SYSTEMS IN BIOMA AREA PAMPA IN RIO GRANDE DO SUL}

\section{ABSTRACT:}

Representing a set of very ancient ecosystems, the Pampas Biome features peculiar flora and fauna and great biodiversity, not fully described by the science. Since the Iberian colonization, extensive livestock (beef and sheep) on native grasslands has been the main economic activity of the region. The progressive introduction and expansion of monocultures and pastures with exotic species have led to a rapid degradation and mischaracterization of natural landscapes of the Pampa. The purpose of this article is to assess the sustainability of different livestock production systems of family farmers in Rio Grande do Sul. It was used the Mesmis method for the sustainability analysis of three groups of identified production systems: $\mathrm{CN}$ (Natural Grassland), $\mathrm{CN}+\mathrm{C}$ (Natural Grassland + other cultives) and CN + S (Natural Grassland + Soybean). A significant difference was identified $(p<0.05)$ for "Productivity" attribute between $\mathrm{CN}+\mathrm{C}$ and $\mathrm{CN}+\mathrm{S}$ systems, the first being greater than the second. For other attributes of sustainability there were no significant differences between the studied production systems.

Keyword: Sustainability. Small livestock farmers. Soybean.

\footnotetext{
${ }^{1}$ Doutora em Extensão Rural pela Universidade Federal de Santa Maria. carolinanicoloso@hotmail.com

${ }^{2}$ Doutor em Resource Management pela University of Edinburgh, Escócia. Professor do Programa de Pós-Graduação em Extensão Rural da Universidade Federal de Santa Maria.vcpsilveira@gmail.com

${ }^{3}$ Mestre em Zootecnia pela Universidade Federal de Santa Maria. Engenheiro Agrônomo da Associação Riograndense de Empreendimentos de Assistência Técnica e Extensão Rural. rfilho@emater.tche.br

${ }^{4}$ Doutor em Zootecnia pela Universidade Federal do Rio Grande do Sul. Professor do Programa de Pós-Graduação em Zootecnia da Universidade Federal de Santa Maria.flfquadros@yahoo.com.br
} 
O Brasil, com uma área de $8.514 .877 \mathrm{~km}^{2}$, é subdivido em seis biomas: Amazônia (49,29\%), Cerrado (23,92\%), Mata Atlântica (13,04\%), Caatinga (9,92\%), Pampa (2,07\%) e Pantanal $(1,76 \%)$, o que se pode visualizar na Figura 1 . O Pampa está restrito ao Estado do Rio Grande do Sul (ele faz parte dos pampas sul-americanos, que se estendem pelo Uruguai e pela Argentina), ocupando uma área de $176.496 \mathrm{~km}^{2}$ o que corresponde a $63 \%$ do território do Estado, portanto o bioma, apesar de representar 2,07\% da área do Brasil, equivale aproximadamente a duas vezes o território de Portugal, que possui uma área total de $92.090 \mathrm{~km}^{2}$.

Figura 1 - Biomas brasileiros e respectivos percentuais em relação ao território total

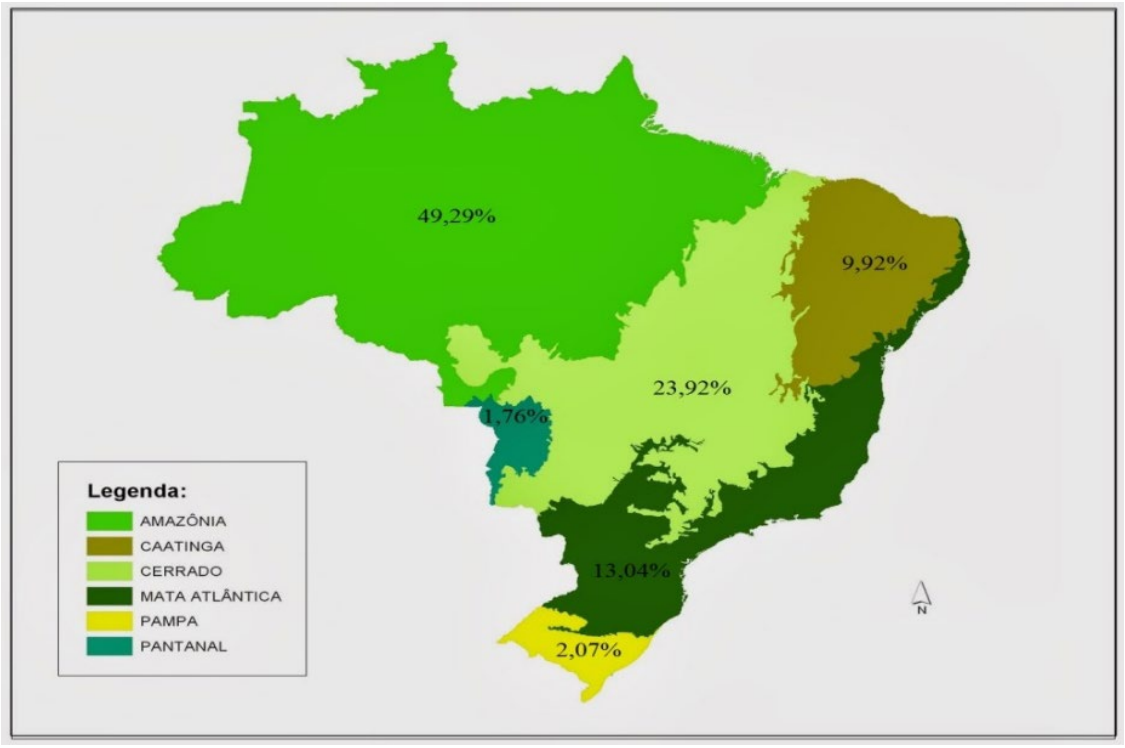

Fonte: Adaptado de MINISTÉRIO..., 2014.

Por ser um conjunto de ecossistemas muito antigos, o Pampa apresenta flora e fauna próprias e grande biodiversidade, ainda não completamente descrita pela ciência. As paisagens naturais do Pampa são variadas, de serras a planícies, de morros rupestres a coxilhas. $\mathrm{O}$ bioma exibe um imenso patrimônio cultural associado à biodiversidade. As paisagens naturais do Pampa caracterizam-se pelo predomínio dos campos nativos, mas há também a presença de matas ciliares, matas de encosta, matas de pau-ferro, formações arbustivas, butiazais, banhados, afloramentos rochosos, etc. Trata-se de um patrimônio natural, genético e cultural de importância nacional e global. Também é no Pampa que se localiza a maior parte do aquífero Guarani (MINISTÉRIO..., 2014). Desde a colonização ibérica, a pecuária extensiva (bovinos de corte e ovinos) sobre os campos nativos tem sido a principal atividade econômica da região. "Além de proporcionar resultados econômicos importantes, tem permitido a conservação dos campos e ensejado o desenvolvimento de uma cultura mestiça singular, de caráter transnacional representada pela figura do gaúcho" (MINISTÉRIO..., 2014).

A dinâmica econômica mundial resulta na constante necessidade se aumentar a produção e produtividade para atender às demandas internas e externas, resultando na expansão de áreas agrícolas e intensificação da atividade. Schlottfeldt (1983) afirma que este processo ocorre via incorporação de novas áreas ao sistema de produção, ou pelo aumento da produtividade dentro de um processo de desenvolvimento excludente socialmente e também com potenciais riscos à preservação dos recursos naturais. A pro- 
gressiva introdução e expansão das monoculturas e das pastagens com espécies exóticas tem levado a uma rápida degradação e descaracterização das paisagens naturais do Pampa. Estimativas de perda de hábitat dão conta de que em 2002 restavam 41,32\% e em 2008 restavam apenas 36,03\% da vegetação nativa do bioma Pampa (MINISTÉRIO..., 2014). O avanço da cultura da soja na região do Pampa constitui um grave problema ainda pouco estudado (PIZZATO, 2013). Este avanço está diretamente ligado ao alto preço alcançado pela soja, decorrente de que esta oleaginosa, além de outros usos, é fonte principal de biodiesel no Brasil.

Silveira, González e Fonseca (2017), estudando as mudanças no uso da terra no Rio Grande do Sul (RS) relacionadas à valorização de grãos no mercado interno e externo, observam que ocorreram mudanças importantes no uso da terra alocadas para cultivos de verão, quando comparam dois períodos: 1990 a 2000 (antes da valorização de grãos no mercado) e de 2000 a 2015 (depois da valorização de grãos no mercado). No bioma Pampa, os autores constataram um aumento nas terras destinadas ao cultivo de soja de 1.192,115 ha, tornando-a a principal cultura comercial deste bioma no ano de 2003. Apesar dos estímulos à produção de girassol como matéria-prima para o biodiesel e a tradição da zona na produção de arroz, não foi o suficiente para deter o avanço da soja na região. Os autores, contudo, demonstram que para o rebanho bovino, por exemplo, houve flutuações entre os dois períodos estudados, destacando que, embora a área de cultivo de soja se expanda sobre áreas anteriormente destinadas à pecuária, as áreas utilizadas para produção de soja no verão em grande parte são utilizadas com pastagens cultivadas no inverno, destinadas à alimentação animal.

No RS, a pecuária familiar desempenha importante papel no que respeita à conservação do bioma Pampa devido às características dos sistemas de manejo que utilizam em práticas que favorecem, historicamente, uma produção mais extensiva e conservacionista. A condição de pecuaristas familiares está regulamentada pelo Decreto n. 48.316, de 31 de agosto de 2011 (RIO GRANDE DO SUL, 2011), que, no seu artigo 30 , determina que pecuaristas familiares são os produtores que atendam simultaneamente às seguintes condições:

1. Tenham como atividade predominante a cria ou a recria de bovinos e/ou caprinos e/ou bubalinos e/ou ovinos com a finalidade de corte.

2. Utilizem na produção trabalho predominantemente familiar, podendo utilizar mão de obra contratada em até cento e vinte dias ao ano.

3. Detenham a posse, a qualquer título, de estabelecimento rural com área total, contínua ou não, inferior a trezentos hectares.

4. Tenham residência no próprio estabelecimento ou em local próximo a ele.

5. Obtenham no mínimo setenta por cento da sua renda provinda da atividade pecuária e não agropecuária do estabelecimento, excluídos os benefícios sociais e os proventos previdenciários decorrentes de atividades rurais.

Diante do cenário agropecuário atual, o que se percebe é que pode estar ocorrendo uma mudança de ritmo e racionalidade da pecuária familiar, provocada pela expansão da agricultura e inovações tecnológicas na pecuária. Consequentemente, é possível que diferentes efeitos advenham a partir da alteração destes sistemas de produção, e estes efeitos ainda necessitam de maiores análises e estudos. Análises que 
medem efeitos em curto prazo ou que considerem apenas aspectos produtivistas e econômicos podem não ser suficientes para avaliar os impactos destas novas dinâmicas de produção, pois não consideram aspectos socioambientais, por exemplo. Assim, analisar a sustentabilidade dos sistemas de produção da pecuária familiar envolvidos neste cenário de valorização de grãos e expansão da cultura da soja, como os seus impactos ambientais, sociais e econômicos, bem como compreender sua dinâmica, é imprescindível para preencher a lacuna de pesquisa existente em relação a estes sistemas de produção.

Para Altieri (2000), a agricultura é afetada pela evolução dos sistemas socioeconômicos e ambientais. Assim, tendo-se o conceito de sustentabilidade apontado por Cavalcanti (1998), em que sustentabilidade é a possibilidade de se obter continuamente condições iguais ou superiores de vida para um grupo de pessoas e seus sucessores em dado ecossistema, para se estudar sistemas agropecuários é necessário conhecer sua sustentabilidade. Diante de uma diversidade de conceitos de sustentabilidade existentes, esta "deve ser vista, estudada e proposta como sendo uma busca permanente de novos pontos de equilíbrio entre diferentes dimensões que podem ser conflitivas entre si em realidades concretas" (CAPORAL; COSTABEBER, 2002, p. 75), e somente pode ser medida posteriormente. O que se ressalta em relação à sustentabilidade, além da compreensão do que realmente é, são as formas de medi-la. Carvalho (1993) também destaca a necessidade de medir sustentabilidade e questiona as formas de realizar essa medição, visto que a prova da sustentabilidade está sempre no futuro.

Neste artigo assume-se sustentabilidade como um conceito dinâmico, complexo e multidimensional, sem definição única, que permite compreender as inter-relações entre aspectos sociais, econômicos e ambientais. Por essas características, segundo Galván-Miyoshi, Masera e López-Ridaura (2008), a sustentabilidade deve ser definida localmente, prestando atenção a diversidade sociocultural e ambiental. Operacionalizar este conceito implica estabelecer uma série de atributos gerais (equidade, produtividade, resiliência, entre outros) que permitem entender a capacidade destes socioecossistemas de serem produtivos, de se autorregularem e se transformarem (GALVÁN-MIYOSHI; MASERA; LÓPEZ-RIDAURA, 2008).

Desta forma, o objetivo deste artigo é avaliar a sustentabilidade de diferentes sistemas de produção da pecuária familiar no RS por intermédio do método Marco para la Evaluación de Sistemas de Manejo de los Recursos Naturales Incorporando Indicadores de Sustentabilidad (Mesmis), ${ }^{1}$ o qual propõe a análise da sustentabilidade por meio de uma estrutura flexível e que se adapta a diferentes níveis de informação e capacidade técnica disponível localmente, com um processo de avaliação participativo. No método Mesmis, a sustentabilidade é concebida de forma dinâmica, multidimensional e específica a um determinado contexto socioambiental e espaçotemporal, em que os sistemas sustentáveis permanecem mudando, e para isso necessitam ter a capacidade de se adaptar sem perder sua funcionalidade (MASERA, 2008), com estas capacidades podendo ser avaliadas mediante um conjunto de atributos que serão descritos posteriormente. 


\section{METODOLOGIA}

Esta pesquisa foi desenvolvida com apoio da Associação Riograndense de Empreendimentos de Assistência Técnica e Extensão Rural (Emater/RS-Ascar), Regional de Santa Maria. A Regional é composta por 35 municípios, dos quais 12 participaram do projeto por intermédio da colaboração de seus técnicos municipais de pecuária (Figura 2). Assim, foram avaliados três diferentes sistemas em 12 municípios (Cacequi, Cachoeira do Sul, Dilermando de Aguiar, Formigueiro, Jaguari, Nova Esperança do Sul, Pinhal Grande, Quevedos, Restinga Seca, São Francisco de Assis, São Sepé, Unistalda), num total de 34 propriedades. Como parte da metodologia, foram identificados pelos técnicos três sistemas de produção realizada por pecuaristas familiares:

$\mathrm{CN}$ - Pecuaristas familiares com sistema de produção em campo nativo.

$\mathrm{CN}+\mathrm{C}-$ Pecuaristas familiares com sistema de produção em campo nativo e presença de diferentes cultivos, para subsistência ou não, exceto soja.

$\mathrm{CN}+\mathrm{S}-$ Pecuaristas familiares com sistema de produção em campo nativo e cultivo de soja.

Figura 2 - Mapa do RS com 12 municípios participantes do projeto em destaque

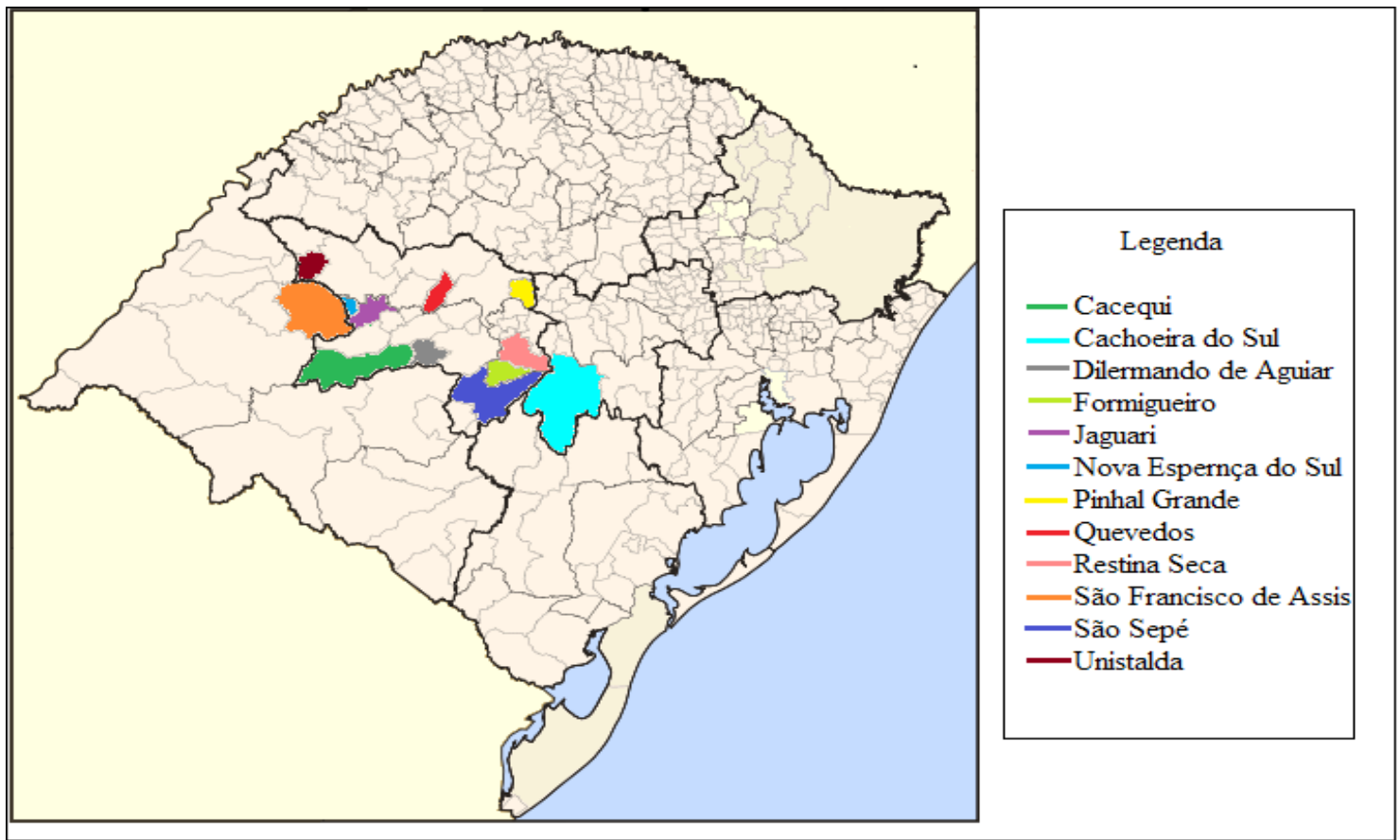

Fonte: Elaborado pelos autores.

Para verificar e analisar a sustentabilidade dos sistemas de produção da pecuária familiar foi utilizada a metodologia do Marco para Evaluación de Sistemas de Manejo de Recursos Naturales Incorporando Indicadores de Sustentabilidad - Mesmis, ${ }^{5}$ proposto por Masera, Astier e López-Ridaura (1999).

5 Mais informações sobre o método Mesmis disponível em: <ttps://www.researchgate.net/publication/299870632_ Sustentabilidad_Y_manejo_de_recursos_naturales_El_Marco_de_evaluacion_MESMIS> 
O método Mesmis, desenvolvido para avaliações de sustentabilidade em agroecossitemas, foi elaborado dentro da concepção de que os sistemas de manejos sustentáveis são aqueles que permanecem em modificação, pois estão sujeitos a alterações provocadas pelo ambiente interno e externo, e com isto devem ter a capacidade de serem produtivos, de se autorregularem e de poderem se transformar sem perder sua funcionalidade (MASERA, 2008). Segundo o autor, estas capacidades podem ser analisadas mediante um conjunto de atributos genéricos ou propriedades sistêmicas fundamentais: produtividade, estabilidade, confiabilidade, resiliência, adaptabilidade, equidade e autogestão.

O quadro Mesmis permite a derivação, medição e monitoramento de indicadores de sustentabilidade como parte de um processo flexível de avaliação sistêmica, participativa, interdisciplinar (LÓPEZ-RIDAURA; MASERA; ASTIER, 2002). O quadro é baseado em sete atributos de sustentabilidade:

(A) Produtividade: é a propriedade do agroecossistema de gerar o nível requerido de bens e serviços, representado pelos ganhos ou rendimentos em um determinado período de tempo. Destes ganhos podem ser representados e medidos por meio de indicadores diretos, por exemplo, as medidas de lucratividade econômica. Ou mediante indicadores indiretos que refletem o uso e manejo dos recursos naturais, avaliando seus efeitos ao longo do tempo.

(B) Estabilidade: é a propriedade do agroecossistema de manter constante a produtividade gerada no decorrer do tempo.

(C) Resiliência: é a capacidade que um agroecossistema apresenta de retornar ao seu potencial de produção após sofrer perturbações.

(D) Confiabilidade: capacidade de um agroecossistema manter os benefícios desejados em níveis próximos aos gerados em condições normais.

(E) Adaptabilidade: capacidade do agroecossistema de reencontrar estabilidade após uma situação adversa.

(F) Equidade: a capacidade do agroecossistema de distribuir, de forma justa, os benefícios e custos resultantes do manejo dos recursos naturais.

(G) Autossuficiência: é a capacidade do agroecossistema de regular e controlar suas relações com a contexto exterior.

Os atributos estabilidade, confiabilidade e resiliência podem ser agrupados (doravante denominados apenas de "estabilidade") para expressar a capacidade do sistema para lidar com a mudança (LÓPEZ-RIDAURA; MASERA; ASTIER, 2002). Juntamente com a adaptabilidade, esses atributos ajudam a analisar a sustentabilidade dos sistemas de produção de uma forma dinâmica que permite considerar o contexto físico e socioeconômico em que operam.

A estrutura operacional Mesmis consiste em seis etapas (SPEELMAN et al., 2007) que são desenvolvidas por intermédio de métodos participativos, em que o resultado de cada etapa é fruto das percepções e contribuições dos atores envolvidos:

Estágio 1 - definição e descrição do sistema ou sistemas a serem avaliados. 
Estágio 2 - identificação dos pontos críticos do sistema: aspectos positivos ou negativos que fornecem força ou vulnerabilidade, ou seja, fatores socioeconômicos, técnicas ou processos que individualmente ou em combinação podem ter um efeito crucial sobre os atributos dos sistemas descritos.

Estágio 3 - seleção dos critérios de diagnóstico e indicadores: o objetivo deste processo é fornecer a necessária ligação entre os atributos e os pontos críticos, de um lado, e os pontos críticos e indicadores, de outro. A diferença entre os critérios de diagnóstico e os indicadores é que o primeiro descreve os atributos de sustentabilidade e o segundo relata um processo específico dentro do sistema.

A operacionalização dos primeiros três estágios do método Mesmis foram desenvolvidos entre os meses de outubro de 2013 e março de 2014. Assim, a definição do objeto de estudo (Estágio 1) foi realizada numa reunião do grupo de pesquisadores e extensionistas, pertencentes à Universidade Federal de Santa Maria (UFSM) e Emater Santa Maria. No segundo momento (Estágio 2), para a identificação dos pontos críticos do sistema foi realizada uma reunião com a presença do grupo de pesquisadores e os técnicos de campo municipais da Emater Santa Maria, em 16 de outubro de 2013, quando foi apresentada a metodologia de trabalho e discutidos os pontos fracos e fortes dos sistemas de produção em estudo, bem como suas oportunidades e fraquezas, por meio de uma análise Swot (Strengths, Weaknesses, Opportunities and Threats - Forças, Fraquezas, Oportunidades e Ameaças), a qual podemos observar no Quadro 1.

Quadro 1 - Swot gerado para os sistemas de produção de pecuária familiar na região central do RS

\begin{tabular}{|c|c|}
\hline Forças & Fraquezas \\
\hline Liquidez & $\begin{array}{c}\text { Plantas invasoras nativas e tóxicas } \\
\text { Dependência de mecanização externa } \\
\text { Problemas tecnológicos da lavoura }\end{array}$ \\
$\begin{array}{c}\text { Proventos como auxílio à renda } \\
\text { Disponibilidade de mão de obra }\end{array}$ & Resistência a mudança \\
Disponibilidade de crédito & Idade \\
Domínio de fatores de produção & Aumento da concentração animal por área \\
Oportunidades & Individualismo \\
\hline Reserva de poupança & Ameaças \\
\hline Menor comprometimento do patrimônio & Sanidade animal \\
Menor endividamento & Endividamento \\
Diversificação da renda & Áreas de solos marginais \\
Rentabilidade da mão de obra & Falta de escala \\
Oportunidade de novos investimentos & Sucessão \\
Capacidade de decisão & Baixa autoestima \\
\hline
\end{tabular}

Fonte: Elaborado pelos autores

O Estágio 3 realizou-se em março de 2014, quando o grupo de pesquisadores envolvidos definiu os critérios de diagnóstico e indicadores (Tabela 1) e elaborou os questionários para a coleta de dados a campo. 
Tabela 1 - Critérios de Diagnóstico, Indicadores, Descrição dos Indicadores e Ponderação, dentro de cada atributo Mesmis, gerados para os sistemas de produção de pecuária familiar na região central do RS

\begin{tabular}{|c|c|c|c|c|}
\hline Atributos & Critérios de Diagnóstico & Indicadores & Descrição dos Indicadores & $\begin{array}{l}\text { Ponderação* } \\
\text { (\%) }\end{array}$ \\
\hline \multirow{5}{*}{$\begin{array}{l}\frac{1}{10} \\
\stackrel{1}{\leq} \\
0 \\
\frac{0}{0} \\
\frac{\pi}{0} \\
\frac{0}{2} \\
\frac{1}{5} \\
\frac{0}{0} \\
\frac{0}{2}\end{array}$} & $\begin{array}{l}\text { Relação entre carga e } \\
\text { capacidade de carga do } \\
\text { campo nativo. }\end{array}$ & Altura do pasto. & $\begin{array}{l}\text { Valores observados }(\mathrm{cm}) \text {. Maior } \\
\text { altura corresponde a maior } \\
\text { sustentabilidade. }\end{array}$ & 40 \\
\hline & $\begin{array}{l}\text { Qualidade estacional, idade } \\
\text { de espécies presentes, } \\
\text { presença de invasoras } \\
\text { pequenas e/ou campo sujo, } \\
\text { solo descoberto. }\end{array}$ & $\begin{array}{l}\text { \% de Forrageiras, } \\
\text { invasoras e } \\
\text { cobertura do solo. }\end{array}$ & $\begin{array}{l}\text { Escala de } 1 \text { a } 6 \text {, onde o valor mais } \\
\text { sustentável corresponde a } 1 \text { (solo } \\
\text { coberto sem invasoras). }\end{array}$ & 40 \\
\hline & Incorporação no sistema. & $\begin{array}{c}\text { Tempo de } \\
\text { incorporação. }\end{array}$ & $\begin{array}{l}\text { Nível } 1 \text { (mais sustentável): } \\
\text { cultivos consolidados. Nível 2: } \\
\text { não consolidados. }\end{array}$ & 8 \\
\hline & Percentual no sistema. & $\begin{array}{l}\text { \% de cultivos no } \\
\text { sistema. }\end{array}$ & $\begin{array}{c}\text { Valores observados (\%). Menor \% } \\
\text { de cultivos corresponde a maior } \\
\text { sustentabilidade. }\end{array}$ & 4 \\
\hline & Tipo de cultura. & $\begin{array}{c}\text { Presença de } \\
\text { diferentes cultivos. }\end{array}$ & $\begin{array}{l}\text { Nível } 1 \text { (mais sustentável): } \\
\text { presença de diferentes cultivos, } \\
\text { exceto soja. Nível 0: cultivo de soja }\end{array}$ & 8 \\
\hline \multirow{5}{*}{ 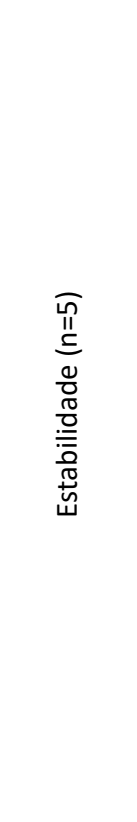 } & $\begin{array}{c}\text { Existência e predisposição de } \\
\text { sucessores a continuar com } \\
\text { atividade. }\end{array}$ & $\begin{array}{l}\text { Existência e } \\
\text { predisposição de } \\
\text { sucessão. }\end{array}$ & $\begin{array}{l}\text { Escala de } 1 \text { a } 4 \text {, onde o valor } \\
\text { mais sustentável corresponde a } \\
1 \text { (existe sucessor). }\end{array}$ & 30 \\
\hline & $\begin{array}{c}\text { Terra em usufruto, existência } \\
\text { de outros bens, quantidade } \\
\text { de herdeiros. }\end{array}$ & $\begin{array}{l}\text { Área de terra/ } \\
\text { herdeiro. }\end{array}$ & $\begin{array}{l}\text { Valores observados, sendo mais } \\
\text { sustentável maior valor de } \mathrm{Ha} / \\
\text { herdeiro. }\end{array}$ & 20 \\
\hline & $\begin{array}{l}\text { Casa, fonte de luz, fonte de } \\
\text { água, locomoção. }\end{array}$ & $\begin{array}{l}\text { Habitação e } \\
\text { transporte. }\end{array}$ & $\begin{array}{c}\text { Escala de } 0 \text { a } 8 \text { (mais } \\
\text { sustentável), considera a oferta e } \\
\text { qualidade de água, luz, habitação } \\
\text { e transporte. }\end{array}$ & 20 \\
\hline & $\begin{array}{l}\text { Serviços de saúde e condições } \\
\text { de trabalho. }\end{array}$ & $\begin{array}{l}\text { Sanidade e } \\
\text { salubridade. }\end{array}$ & $\begin{array}{l}\text { Escala de } 0 \text { a } 5 \text { (mais } \\
\text { sustentável), considera a oferta e } \\
\text { qualidade de serviços de saúde e } \\
\text { condições de trabalho. }\end{array}$ & 10 \\
\hline & $\begin{array}{l}\text { Aposentadoria/prestação } \\
\text { de serviço/outras rendas/ } \\
\text { produção animal. }\end{array}$ & $\begin{array}{c}\% \text { da renda } \\
\text { de origem da } \\
\text { produção animal. }\end{array}$ & $\begin{array}{l}\text { Percentual da renda total } \\
\text { com origem da produção } \\
\text { animal observado, sendo } \\
\text { mais sustentável a maior } \\
\text { porcentagem. }\end{array}$ & 20 \\
\hline \multirow{4}{*}{ 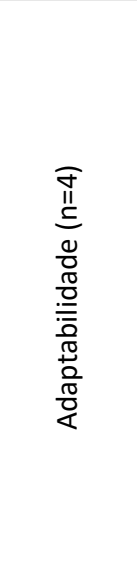 } & Nível de educação formal & Formação formal & $\begin{array}{l}\text { Escala de } 0 \text { a } 5 \text {, onde } 0 \\
\text { representa ausência de } \\
\text { educação formal e nível } 5 \text { (mais } \\
\text { sustentável), curso superior na } \\
\text { área agropecuária. }\end{array}$ & 12,5 \\
\hline & $\begin{array}{c}\text { Capacitação produtiva e não } \\
\text { produtiva nos últimos três } \\
\text { anos. }\end{array}$ & $\begin{array}{l}\text { № cursos de } \\
\text { capacitação nos } \\
\text { últimos } 3 \text { anos. }\end{array}$ & $\begin{array}{l}\text { Valores observados, quanto mais } \\
\text { cursos, mais sustentável. }\end{array}$ & 12,5 \\
\hline & $\begin{array}{l}\text { Nível de participação em } \\
\text { espaços coletivos em geral. }\end{array}$ & $\begin{array}{l}\text { № de grupos de } \\
\text { espaço coletivo } \\
\text { em geral que } \\
\text { participa. }\end{array}$ & $\begin{array}{l}\text { Valores observados; maior } \\
\text { participação, mais sustentável. }\end{array}$ & 50 \\
\hline & Participação no Sindicato. & $\begin{array}{l}\text { Tipo de } \\
\text { participação } \\
\text { sindical. }\end{array}$ & $\begin{array}{l}\text { Escala de } 0 \text { a } 2 \text { (mais } \\
\text { sustentável), onde } 2 \text { participa } \\
\text { efetivamente de sindicatos. }\end{array}$ & 25 \\
\hline
\end{tabular}




\begin{tabular}{|c|c|c|c|c|}
\hline \multirow{5}{*}{ 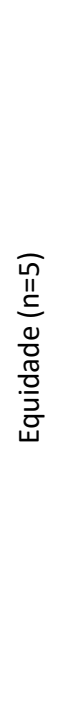 } & Bem-estar animal. & $\begin{array}{l}\text { Água de qualidade, } \\
\text { sombra e manejo. }\end{array}$ & $\begin{array}{c}\text { Escala de } 0 \text { a } 4 \text { (mais } \\
\text { sustentável), considera oferta } \\
\text { e qualidade da água, sombra e } \\
\text { manejo para animais. }\end{array}$ & 14 \\
\hline & Medicamentos para parasitas. & $\begin{array}{l}\text { Resistência a } \\
\text { parasitas internos } \\
\text { e externos. }\end{array}$ & $\begin{array}{c}\text { Escala de } 0 \text { a } 4 \text { (mais sustentável), } \\
\text { considera a existência de } \\
\text { resistência a parasitas em ovinos } \\
\text { e bovinos }\end{array}$ & 24 \\
\hline & Campo nativo melhorado. & $\% \mathrm{CN}$ melhorado & $\begin{array}{l}\text { Valores observados. Menor } \\
\text { percentual é a maior } \\
\text { sustentabilidade. }\end{array}$ & 24 \\
\hline & Uso de pastagem cultivada. & $\begin{array}{l}\% \text { de pastagem } \\
\text { cultivada no } \\
\text { sistema. }\end{array}$ & $\begin{array}{l}\text { Valores observados. Quanto } \\
\text { menor o percentual, maior a } \\
\text { sustentabilidade. }\end{array}$ & 24 \\
\hline & Padronização do rebanho. & $\begin{array}{l}\text { Escala de } \\
\text { padronização do } \\
\text { rebanho. }\end{array}$ & $\begin{array}{c}\text { Escala de } 0 \text { a } 7 \text { (mais } \\
\text { sustentável), com } 0 \text { para não } \\
\text { padronizado e } 7 \text { para rebanho } \\
\text { bovino e ovino padronizado. }\end{array}$ & 14 \\
\hline \multirow{3}{*}{ 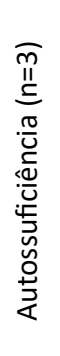 } & Propriedade da terra. & $\begin{array}{l}\% \text { da superfície } \\
\text { total como } \\
\text { proprietário. }\end{array}$ & $\begin{array}{l}\text { Valores observados. Quanto } \\
\text { maior o percentual, maior a } \\
\text { sustentabilidade. }\end{array}$ & 40 \\
\hline & Nível de endividamento. & $\begin{array}{l}\text { \% da dívida total } \\
\text { anual/receita } \\
\text { bruta. }\end{array}$ & $\begin{array}{l}\text { Valores observados. Quanto } \\
\text { menor o percentual, maior a } \\
\text { sustentabilidade. }\end{array}$ & 40 \\
\hline & Sistema de produção. & $\begin{array}{l}\text { \% da dieta em } \\
\text { suplementação. }\end{array}$ & $\begin{array}{l}\text { Valores observados. Quanto } \\
\text { menor o percentual, maior a } \\
\text { sustentabilidade. }\end{array}$ & 20 \\
\hline
\end{tabular}

* O total ponderado por atributo é $100 \%$.

Fonte: Elaborado pelos autores.

Entendemos que o agroecossistema pode ser caracterizado como um ecossistema submetido pelo homem a modificações contínuas de seus componentes bióticos e abióticos para a produção de alimentos e fibras. O gestor (fator humano) agirá sobre o ecossistema conforme as condições em que interage. Assim, ao ter acesso à energia de fora da propriedade (elétrica ou fóssil) não estará usando, por exemplo, lenha para aquecer água, promovendo, assim, a estabilidade para o sistema.

Ao realizar a produção animal estamos realizando o manejo dos recursos naturais. Como o agroecossistema reage a esta ação é o que consideramos na equidade. Neste caso, o bem-estar animal e a padronização do rebanho podem ser considerados um benefício. O campo nativo melhorado também pode ser um benefício quando comparado ao uso de pastagem cultivada e ao uso de medicamentos para parasitas que são um custo para o sistema. Nesse sentido, quanto mais pastagem e mais resistência a medicamentos maior será o custo para este agroecossitema.

Estágio 4 - medição e monitoramento de indicadores selecionados na etapa anterior. No período de março a junho de 2014 foi aplicado o questionário para coleta de dados em 34 sistemas de produção da pecuária familiar que fazem parte do setor de atuação da Emater Santa Maria. O questionário estava composto por questões que permitem responder aos indicadores estabelecidos no estágio anterior. 
Estágio 5 - integração dos resultados: valores de referência foram estabelecidos para cada indicador usando valores de referência encontrados na literatura ou valores específicos para o estudo de caso em análise. Os valores de referência ótimos variam de acordo com a natureza dos indicadores. Para cada atributo de sustentabilidade, os indicadores foram ponderados para refletir a importância relativa que possuem para explicar a sustentabilidade do sistema. Este processo, muitas vezes, dependente de uma pontuação subjetiva (MEUL et al., 2008). Os pesquisadores e extensionistas, que participaram das reuniões nos Estágios 1, 2 e 3, também fizeram a classificação dos indicadores, dentro de cada atributo de sustentabilidade, em ordem de importância (o peso mais baixo foi dado ao indicador de menor importância). Os indicadores utilizados são diversificados e expressos em ambos os sentidos, qualitativos e quantitativos. Em seguida, todos os indicadores tiveram os valores transformados numa escala de 0 a 100, correspondendo ao pior (0) e ao melhor (100) valor. Estes valores dos indicadores e seu peso foram utilizados para calcular os atributos de sustentabilidade dos sistemas de produção estudados (\%).

Estágio 6-conclusões e recomendações: os sistemas de produção identificados foram agrupados e a avaliação é expressa em termos comparativos entre os tipos de sistemas de produção. Para a análise dos dados foi utilizado o Programa Estatístico SPSS, versão 22.0 (SPSS Inc., Chicago, Estados Unidos) e, aplicamos Anova e teste de Tukey, em nível de $5 \%$ de significância, para comparação de médias.

\section{RESULTADOS E DISCUSSÃO}

Os 34 sistemas de produção que compõem esta análise de sustentabilidade estão distribuídos entre os municípios de Cachoeira do Sul, Restinga Seca, Formigueiro, São Sepé, Pinhal Grande, Quevedos, Jaguari, Unistalda, São Francisco de Assis, Nova Esperança do Sul e Dilermando de Aguiar, localizados sob diferentes condições agroecológicas do Bioma Pampa. A precipitação média na zona de estudo é de $1.776 \mathrm{~mm} / \mathrm{ano}$, distribuídos em uma média de 96 dias/ano, e a temperatura média dia anual é de 20,1ํㅡ, alcançando máximas que superam os 40 ㅇ C em períodos mais quentes e temperaturas mínimas que atingem valores negativos no inverno.

Na Tabela 2 podemos observar dados que nos permitem uma caracterização inicial dos três sistemas de produção da pecuária familiar estudados, a qual reflete as médias entre todas as propriedades pertencentes a cada sistema de produção. Esta caracterização foi realizada de forma não comparativa, haja vista a heterogeneidade dos sistemas de produção.

Idade do titular da propriedade está, em média, entre 50 e 55 anos. Os sistemas de produção $\mathrm{CN}, \mathrm{CN}+\mathrm{C}$ e $\mathrm{CN}+\mathrm{S}$ apresentam SAU de 59,54 ha, 80,86 ha e 116,41 ha, respectivamente. Em consequência de ter a SAU mais elevada, o sistema de produção $\mathrm{CN}+\mathrm{S}$, também apresenta maior UA, de 98,24 UA, superando os sistemas $\mathrm{CN}$, com 58,02 $\mathrm{UA}$, e o sistema $\mathrm{CN}+\mathrm{C}$, com 59,46 UA. 
Tabela 2 - Médias para as características gerais dos sistemas de produção CN, $\mathrm{CN}+\mathrm{C}$ e CN+S na região central do RS, em 2014

\begin{tabular}{|c|c|c|c|}
\hline & $\begin{array}{c}\mathrm{CN} \\
(\mathrm{n}=12)\end{array}$ & $\begin{array}{l}\mathrm{CN}+\mathrm{C} \\
(\mathrm{n}=9)\end{array}$ & $\begin{array}{l}C N+S \\
(n=13)\end{array}$ \\
\hline Idade do titular & 54 & 50 & 55 \\
\hline $\mathrm{SAU}^{1}$ & 59,54 & 80,86 & 166,41 \\
\hline$U^{2}$ & 58,02 & 59,46 & 98,28 \\
\hline Capacidade de gerar excedente & 0,18 & 0,23 & 0,19 \\
\hline № terneiros/fêmea em idade reprodutiva & 0,29 & 0,35 & 0,31 \\
\hline UA/SAU & 0,97 & 0,74 & 0,59 \\
\hline UTH $^{3}$ familiar & 1,92 & 2,11 & 2,27 \\
\hline SAU/UTH familiar & 36,28 & 51,20 & 74,38 \\
\hline UA/UTH familiar & 34,41 & 38,41 & 46,02 \\
\hline $\begin{array}{l}\text { \% de propriedades que utilizam algum tipo de mão de obra não } \\
\text { familiar no sistema }\end{array}$ & 41,67 & 77,78 & 30,77 \\
\hline Custos/SAU a & 747,42 & 750,31 & 452,65 \\
\hline Custos/UA ${ }^{a}$ & 735,28 & 820,69 & 918,48 \\
\hline Receita líquida/SAU a & 272,40 & 600,08 & 379,59 \\
\hline Receita líquida/UTH familiar a & $11.863,18$ & $11.836,26$ & $22.737,80$ \\
\hline
\end{tabular}

Fonte: Elaborado pelos autores.

O indicador Capacidade de gerar excedente refere-se à taxa de desfrute do sistema de produção. Pelas características dos dados coletados não foi possível calcularmos a taxa de desfrute por meio da fórmula convencional. Assim, obtivemos, mediante dados como receita em vendas de animais e preço do quilo do peso vivo, o número de UAs comercializadas. A capacidade de gerar excedente foi então calculada ao dividirmos as UAs comercializadas pelo número total de animais existentes. O melhor desempenho para este indicador foi do sistema $\mathrm{CN}+\mathrm{C}$, seguido do sistema $\mathrm{CN}+\mathrm{S}$ e $\mathrm{CN}$, que apresentou o resultado menor entre os três.

O número de terneiros/fêmeas em idade reprodutiva, embora não seja um índice zootécnico utilizado, sinaliza uma tendência a um melhor desempenho do manejo reprodutivo do sistema $\mathrm{CN}+\mathrm{C}$, que apresentou valor de 0,35 , superando assim os sistemas $\mathrm{CN}$ e CN+S. O indicador UA/SAU representa a taxa de lotação animal de cada sistema de produção. O sistema $\mathrm{CN}$ apresentou uma taxa de lotação de 0,97 UA/hectare de SAU. Os sistemas $\mathrm{CN}+\mathrm{C}$ e $\mathrm{CN}+\mathrm{S}$, apresentaram 0,74 e 0,59 UA/ hectares de $\mathrm{SAU}$, respectivamente.

A utilização da mão de obra familiar foi medida com o uso do índice UTH, e o sistema que apresentou maior utilização e disponibilidade de mão de obra familiar foi o sistema $\mathrm{CN}+\mathrm{S}$, com 2,27 UTH familiar. Embora apresente a maior UTH, cada UTH no sistema $\mathrm{CN}+\mathrm{S}$ representa o cuidado de 74,38 hectares de SAU e 46,02 UA, de acordo com os indicadores SAU/UTH e UA/UTH, superando os sistemas CN e CN+C. Quanto à utilização de mão de obra contratada, $77,78 \%$ das propriedades rurais que compõem 0 sistema $\mathrm{CN}+\mathrm{C}$ fazem uso deste tipo de serviço, enquanto que nos sistemas $\mathrm{CN}$ e $\mathrm{CN}+\mathrm{S}$, 
$41,66 \%$ e $30,77 \%$ das propriedades contratam mão de obra não familiar. Cabe ressaltar que, embora todos os sistemas realizem esta prática, ela se dá em períodos curtos, como alguns dias ou meses do ano, sendo que apenas duas das propriedades rurais estudadas apresentavam um trabalhador permanente contratado. Nos demais casos a contratação de mão de obra não familiar ocorre em períodos como plantio/safra de cultivos, ou para o manejo esporádico dos animais, e os pagamentos dão-se não somente em moeda corrente, mas também com a troca da prestação de serviço por determinados produtos de autoconsumo e também a permuta de serviços.

Os custos de produção/hectare de SAU foram superiores no sistema $\mathrm{CN}+\mathrm{C}$, porém muito próximos ao sistema $\mathrm{CN}$, observando valores de $\mathrm{R} \$ 750,31$ e $\mathrm{R} \$ 747,42$, respectivamente. Já o sistema $\mathrm{CN}+\mathrm{S}$ apresentou o custo de $\mathrm{R} \$ 452,65 /$ hectare de $\mathrm{SAU}$. Em relação ao custo/UA, o sistema $\mathrm{CN}+\mathrm{S}$ apresentou o maior valor, seguido do sistema $\mathrm{CN}+\mathrm{C}$ e $\mathrm{CN}$, com menor valor. Quanto às receitas, o sistema $\mathrm{CN}+\mathrm{C}$ obteve o melhor resultado, com uma receita líquida de $\mathrm{R} \$ 600,08 /$ hectare de SAU. O valor inferior entre os três sistemas foi o apresentado pelo sistema $\mathrm{CN}$, contudo a remuneração da mão de obra familiar tem melhor resultado no sistema $\mathrm{CN}+\mathrm{S}$ com o valor de $\mathrm{R} \$ 22.737,80 / \mathrm{UTH}$ familiar, superando os demais sistemas, que alcançaram resultados muito próximos, de $\mathrm{R} \$ 11.863,18 / \mathrm{UTH}$ familiar para o sistema CN e R\$11.836,26/UTH familiar para o sistema CN+C.

O resultado da análise de sustentabilidade proposta para os três sistemas avaliados, antes caracterizados, pode ser observado na Figura 3. Os três sistemas de produção da pecuária familiar estudados apresentam valores semelhantes para os atributos Autossuficiência, Equidade e Adaptabilidade, destacando-se que para os dois primeiros atributos mencionados estes valores foram superiores a $70 \%$ e $50 \%$, respectivamente, e para o último os valores de sustentabilidade obtidos foram em torno de $35 \%$. Para o atributo Estabilidade observa-se uma maior diferença numérica entre os índices obtidos, que estão entre $48 \%$ e $58 \%$.

Figura 3 - Sustentabilidade dos sistemas de produção por atributo dos sistemas de produção $\mathrm{CN}, \mathrm{CN}+\mathrm{C}$ e CN+S na região central do RS, em 2014

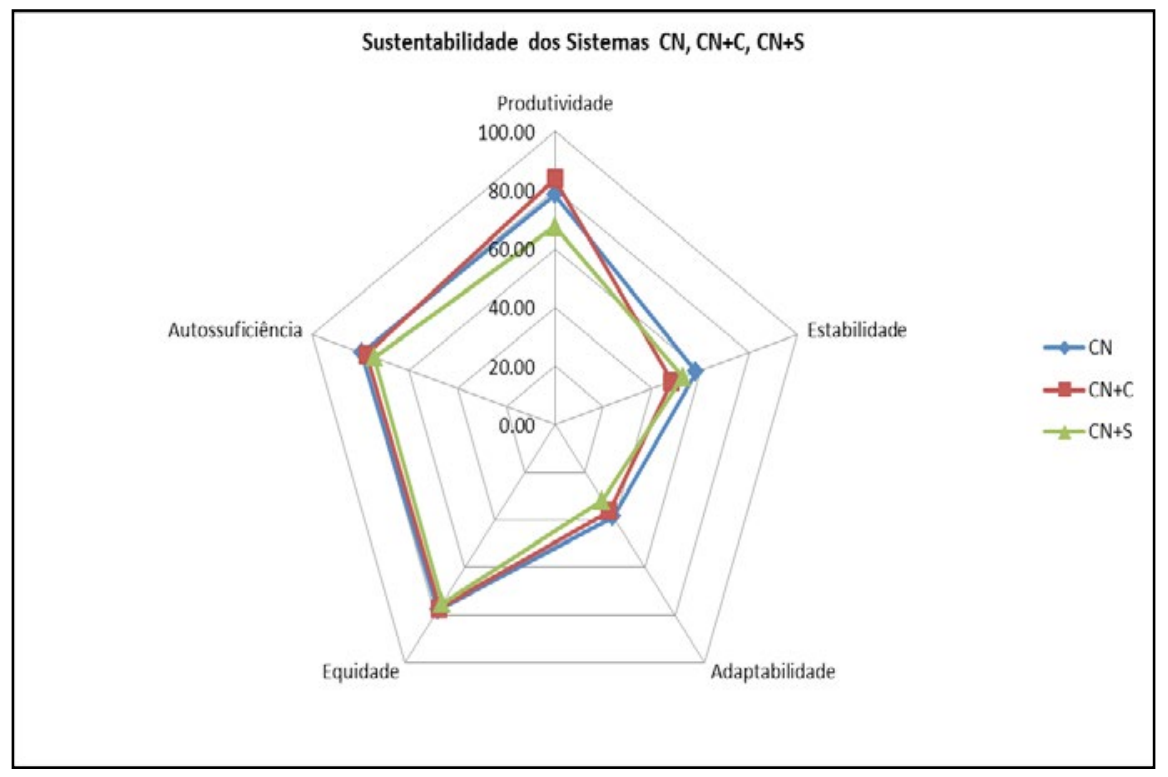

Fonte: Elaborado pelos autores. 
Quanto ao atributo Produtividade, este é o que apresenta maior distanciamento entre os resultados para os três sistemas. Embora na Figura 3 se identifique diferenças entre os valores obtidos para cada um dos sistemas, estas não resultaram em diferenças estatísticas, exceto para o atributo produtividade, como podemos observar na Tabela 3.

Tabela 3 - Médias obtidas para os atributos de Sustentabilidade dos sistemas de produção $\mathrm{CN}, \mathrm{CN}+\mathrm{C}$ e CN+S na região central do RS, em 2014

\begin{tabular}{ccccccc}
\hline Sistemas & N & Produtividade & Estabilidade & Adaptabilidade & Equidade & Autossuficiência \\
CN & 12 & $78,41^{\mathrm{a}}$ & $58,15^{\mathrm{a}}$ & $38,75^{\mathrm{a}}$ & $77,94^{\mathrm{a}}$ & $79,67^{\mathrm{a}}$ \\
$\mathbf{C N}+\mathbf{C}$ & 9 & $83,89^{\mathrm{a}}$ & $48,16^{\mathrm{a}}$ & $36,32^{\mathrm{a}}$ & $77,10^{\mathrm{a}}$ & $77,63^{\mathrm{a}}$ \\
$\mathbf{C N}+\mathbf{S}$ & 13 & $67,64^{\mathrm{b}}$ & $52,75^{\mathrm{a}}$ & $31,78^{\mathrm{a}}$ & $75,02^{\mathrm{a}}$ & $74,29^{\mathrm{a}}$ \\
\hline
\end{tabular}

Anova. Mesmo atributo com letras diferentes indica diferenças significativas entre os sistemas $(p<0.05)$.

Fonte: Elaborado pelos autores.

O teste de comparação de médias identificou diferença significativa para o atributo Produtividade, em que a diferença se verifica entre os sistemas $\mathrm{CN}+\mathrm{C}$ e $\mathrm{CN}+\mathrm{S}$. O sistema de produção $\mathrm{CN}$ não apresentou diferença significativa com os demais sistemas. $\mathrm{O}$ atributo Produtividade é composto por cinco indicadores com diferentes ponderações, conforme descrição na Tabela 1. Ao analisarmos estes indicadores podemos compreender melhor as diferenças significativas para este atributo.

Entre os indicadores, o Percentual de cultivos no sistema demonstra a proporção entre hectares de campo nativo e áreas de cultivos, incluindo forrageiros, nos sistemas de produção. O sistema $\mathrm{CN}+\mathrm{S}$ foi o que apresentou pior resultado para este indicador, com maiores áreas de cultivos que os demais sistemas, indicando possível supressão de áreas de pastos naturais para o estabelecimento de cultivos. Assim, há uma penalização à soja por sua capacidade de avançar reduzindo áreas de campo nativo, devido a questões econômicas comentadas anteriormente (PIZZATO, 2013), dado que o avanço da soja sobre áreas de vegetação nativa no bioma Pampa é a problematização central deste artigo. Entre os sistemas CN E CN+C não houve diferença significativa para este indicador (Tabela 4).

Para o indicador Presença de diferentes cultivos foi pontuada a diversificação por meio da presença de cultivos, exceto o monocultivo da soja, assumindo que a diversificação resulte em maior sustentabilidade. Obviamente, o sistema $\mathrm{CN}+\mathrm{S}$ obteve o pior resultado, apresentando diferença significativa com os demais sistemas, que resultaram estatisticamente iguais entre si.

Tabela 4 - Médias ponderadas obtidas para os indicadores de produtividade (\%) dos sistemas de produção CN, CN+C e CN+S na região central do RS, em 2014

\begin{tabular}{lccc}
\hline Indicadores de Produtividade & $\mathbf{C N}$ & $\mathbf{C N}+\mathbf{C}$ & $\mathbf{C N}+\mathbf{S}$ \\
Altura do pasto & $30,71^{\mathrm{a}}$ & $32,57^{\mathrm{a}}$ & $28,08^{\mathrm{a}}$ \\
Forrageiras invasoras e cobertura do solo & $29,33^{\mathrm{a}}$ & $34,67^{\mathrm{a}}$ & $31,38^{\mathrm{a}}$ \\
Tempo de incorporação & $6,7^{\mathrm{a}}$ & $5,33^{\mathrm{a}}$ & $6,15^{\mathrm{a}}$ \\
Percentual de cultivos no sistema & $3,70^{\mathrm{a}}$ & $3,33^{\mathrm{a}}$ & $2,03^{\mathrm{b}}$ \\
Presença de diferentes cultivos & $8,00^{\mathrm{a}}$ & $8,00^{\mathrm{a}}$ & $0,00^{\mathrm{b}}$ \\
\hline
\end{tabular}

Anova. Mesmo indicador com letras diferentes indica diferenças significativas entre os sistemas $(p<0.05)$.

Fonte: Elaborado pelos autores. 
Os resultados para os indicadores do atributo Produtividade também podem ser identificados na Figura 4, que nos proporciona uma visão mais integrada dos efeitos de cada indicador nos resultados obtidos para Produtividade em cada sistema. Na figura percebe-se claramente que o ponto crítico da avaliação está no indicador Presença de outros cultivos. Devido aos demais indicadores, incluindo altura do pasto, forrageiras invasoras e cobertura do solo (ambos de maior peso para Produtividade), assim como Tempo de incorporação no sistema (menor peso), não diferirem estatisticamente em seus resultados, contribuíram para que o sistema $\mathrm{CN}$ apresente diferenças não significativas com os demais sistemas.

Figura 4 - Indicadores do atributo Produtividade (\%) dos sistemas de produção CN, $\mathrm{CN}+\mathrm{C}$ e CN+S na região central do RS, em 2014

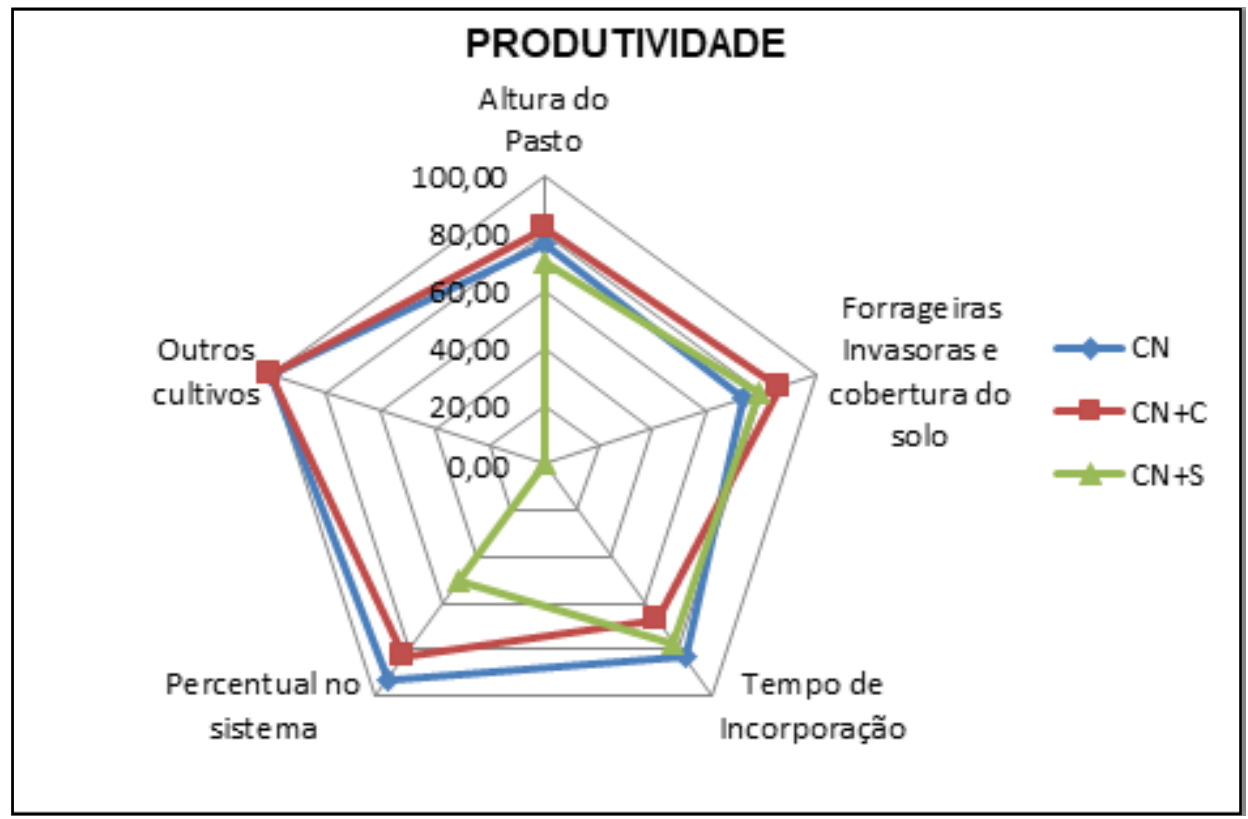

Fonte: Elaborado pelos autores.

A carga animal utilizada pelos produtores é medida indiretamente pelas condições da altura do pasto (indicador), considerando a máxima sustentabilidade com uma altura do pasto acima de 10 centímetros. O nível de degradação do campo nativo refere-se às condições de preservação destas pastagens naturais (indicador Forrageiras invasoras e cobertura do solo) tendo estabelecido que a cobertura mínima do solo deva ser de $90 \%$ sem a presença de invasoras exóticas (principalmente capim annoni - Eragrostis plana Nees). A preservação está ligada diretamente à cobertura de solo e à invasão de plantas exóticas. Nos diferentes sistemas avaliados todos reportam a participação de capim annoni com no mínimo $10 \%$ de presença na cobertura vegetal.

Severo e Miguel (2006), ao analisarem a sustentabilidade dos sistemas de produção de bovinos de corte no RS, referem maior produtividade em alguns dos sistemas de produção que se dedicavam exclusivamente à produção animal, sem produção vegetal. Os autores atribuíram este resultado a maiores taxas de lucro, agregação de valor, geração de renda/SAU e valor agregado por UTH, indicando uma maior eficiência na utilização dos recursos disponíveis para estes sistemas. No caso dos sistemas CN, $\mathrm{CN}+\mathrm{C}$ e $\mathrm{CN}+\mathrm{S}$, embora não haja diferenças significativas, a Figura 4 revela a tendência do sistema $\mathrm{CN}$ e $\mathrm{CN}+\mathrm{C}$ a uma melhor utilização dos recursos disponíveis, que para os 
critérios determinados pelos pesquisadores representam maior produtividade. Quanto aos sistemas $\mathrm{CN}+\mathrm{S}$, podemos afirmar que é menos eficiente na utilização de recursos e, consequentemente, de menor produtividade que o sistema $\mathrm{CN}+\mathrm{C}$, considerando os indicadores avaliados dentro deste atributo. $O$ que não significa que, sobre aspectos diretos e exclusivamente econômicos, isto se reflita.

Para o atributo de sustentabilidade Estabilidade, não foram encontradas diferenças significativas entre as médias dos três sistemas de produção estudados (Tabela 3). Tendo presente que a estabilidade de um agroecossistema é a sua capacidade de manter constante a produtividade gerada ao longo do tempo, os índices alcançados demonstram as dificuldades que estão ligadas a questões da Estabilidade dos sistemas, quando o índice mais alto foi atingido pelo sistema $\mathrm{CN}$, superando escassamente os $50 \%$ de sustentabilidade para o atributo (Figura 3 ).

$O$ atributo Estabilidade está composto de cinco indicadores com diferentes ponderações dentro do atributo e comparando as médias obtidas para cada indicador não houve diferenças significativas entre elas (Tabela 5 ).

Tabela 5 - Médias ponderadas obtidas para os indicadores de estabilidade (\%) dos sistemas de produção $\mathrm{CN}, \mathrm{CN}+\mathrm{C}$ e CN+S na região central do RS, em 2014

\begin{tabular}{lccc}
\hline Indicadores de estabilidade & $\mathbf{C N}$ & $\mathbf{C N + C}$ & $\mathbf{C N + S}$ \\
Existência e predisposição de sucessão & $25^{\mathrm{a}}$ & $20^{\mathrm{a}}$ & $24,62^{\mathrm{a}}$ \\
Ha/herdeiro & $1,42^{\mathrm{a}}$ & $1,84^{\mathrm{a}}$ & $4,08^{\mathrm{a}}$ \\
Habitação e transporte & $14,44^{\mathrm{a}}$ & $10,01^{\mathrm{a}}$ & $10,94^{\mathrm{a}}$ \\
Sanidade e salubridade & $3,83^{\mathrm{a}}$ & $4,67^{\mathrm{a}}$ & $4,62^{\mathrm{a}}$ \\
$\%$ da renda de origem da produção animal & $13,46^{\mathrm{a}}$ & $11,66^{\mathrm{a}}$ & $8,5^{\mathrm{a}}$ \\
\hline
\end{tabular}

Anova $(\mathrm{p}<0.05)$.

Fonte: Elaborado pelos autores.

Entre os indicadores, a Existência e predisposição à sucessão possui maior peso, contribuindo com $30 \%$ do índice do atributo. Para este indicador os resultados foram relativamente satisfatórios, indicando que existem sucessores dispostos a seguir com a atividade nos três sistemas de produção, contudo os resultados para o indicador $\mathrm{Ha} /$ herdeiro tornam a questão da sucessão um ponto crítico para a estabilidade dos sistemas. Na Figura 5 pode-se observar os valores não ponderados obtidos para cada indicador de Estabilidade. De acordo com a Figura 5, o indicador $\mathrm{Ha} /$ herdeiro atingiu seu resultado máximo com o sistema $\mathrm{CN}+\mathrm{S}$, o qual alcançou pouco mais de $20 \%$, em uma escala de 0 a $100 \%$. Os demais sistemas obtiveram resultados ainda inferiores. Isto significa que, no momento da coleta de dados, em caso de ocorrer sucessão, os sistemas $\mathrm{CN}, \mathrm{CN}+\mathrm{C}$ e $\mathrm{CN}+\mathrm{S}$ transmitiram a cada um dos herdeiros 18.46, 23.86 e 53.07 hectares de terras. 
Figura 5 - Indicadores do atributo Estabilidade (\%) dos sistemas de produção CN, $\mathrm{CN}+\mathrm{C}$ e CN+S na região central do RS, em 2014

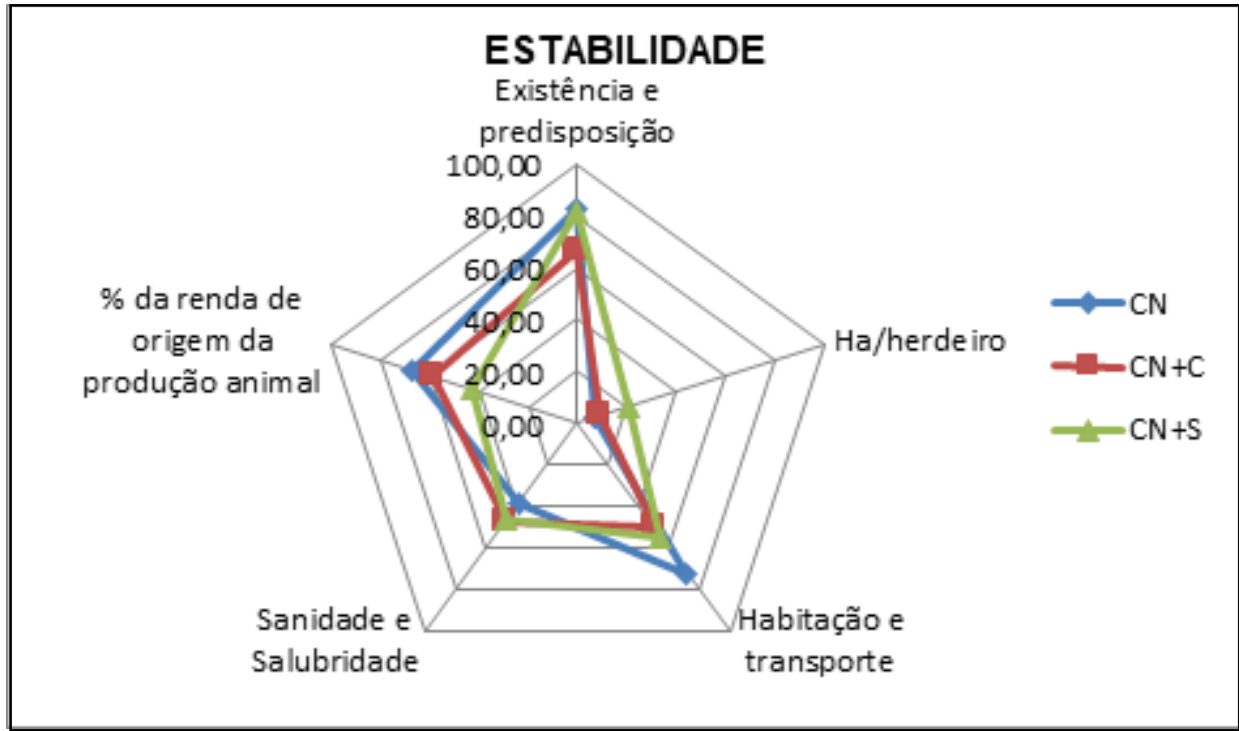

Fonte: Elaborado pelos autores.

Com estes resultados, em caso de sucessão, poderia ser inviável a manutenção dos sistemas tal como o avaliado pela limitação de área produtiva tendo em vista que os herdeiros podem recorrer a alternativas como arrendamento de áreas, compra de novas áreas (na melhor das hipóteses), busca por diferentes trabalhos como fonte de renda ou até mesmo a venda das terras herdadas.

Para o indicador Habitação e transporte o resultado máximo foi obtido pelo sistema CN. Este indicador considerou as condições de habitação mediante o número de pessoas por quarto, oferta e qualidade da água, oferta de luz elétrica e disponibilidade de transporte. Já para o indicador Sanidade e salubridade foram consideradas a existência e qualidade de serviço de saúde e também as condições de trabalho, em que os resultados foram bastante próximos. O sistema $\mathrm{CN}$ obteve $3,83 \%$ e os sistemas $\mathrm{CN}+\mathrm{C}$ e $\mathrm{CN}+\mathrm{S}$ atingiram $4,67 \%$ e 4,62\%, respectivamente.

O indicador \% da renda de origem da produção animal considera mais sustentável um sistema quanto maior for sua renda advinda da produção animal. Com isso, buscou-se detectar diferentes fontes de renda, como aposentadorias, rendas de prestação de serviços ou trabalho assalariado fora do sistema de produção e rendas oriundas de cultivos. Os três sistemas de produção apresentaram rendas exteriores ao sistema e diferenças significativas não foram identificadas entre os sistemas. No sistema $\mathrm{CN}+\mathrm{S}$, O resultado reflete diretamente a alta valorização da soja, conforme menciona Pizzato (2013), o que leva os produtores a destinarem cada vez mais o uso da terra para este cultivo.

Para o atributo Adaptabilidade, a Tabela 3 mostra que não houve diferenças significativas entre as médias dos três sistemas de produção da pecuária familiar em análise. Considerando que o atributo Adaptabilidade retrata a capacidade de um agroecossistema reencontrar equilíbrio após situações adversas, a preparação advinda da educação formal, bem como o acesso e troca de informações oriundas de diferentes formas e meios, pode ampliar a capacidade de percepção, julgamento e tomadas de decisão 
diante de momentos críticos os quais certamente os produtores rurais enfrentam na gestão da atividade. Desta forma, cabe ressaltar o baixo desempenho atingido por todos os sistemas de produção. Na Figura 3 podemos observar que dentre os cinco atributos de sustentabilidade, a Adaptabilidade apresentou os piores resultados, não alcançando os $40 \%$ de sustentabilidade em nenhum dos sistemas.

$\mathrm{O}$ índice de Adaptabilidade foi constituído por quatro indicadores com distintas ponderações. De acordo com a Tabela 6, não existem diferenças significativas entre os variados sistemas para as médias obtidas para cada indicador de Adaptabilidade.

Tabela 6 - Médias ponderadas obtidas para os indicadores de adaptabilidade (\%) dos sistemas de produção CN, CN+C e CN+S na região central do RS, em 2014

\begin{tabular}{lccc}
\hline Indicadores de adaptabilidade & $\mathbf{C N}$ & $\mathbf{C N}+\mathbf{C}$ & $\mathbf{C N + S}$ \\
Educação formal & $2,29^{\mathrm{a}}$ & $0,56^{\mathrm{a}}$ & $1,73^{\mathrm{a}}$ \\
№ cursos de capacitação nos últimos três anos & $2,6^{\mathrm{a}}$ & $3,82^{\mathrm{a}}$ & $0,72^{\mathrm{a}}$ \\
№ de grupos de espaço coletivo em geral que participa & $15,1^{\mathrm{a}}$ & $18,06^{\mathrm{a}}$ & $17,79^{\mathrm{a}}$ \\
Tipo de participação sindical & $18,75^{\mathrm{a}}$ & $13,89^{\mathrm{a}}$ & $11,54^{\mathrm{a}}$ \\
\hline
\end{tabular}

Anova $(p<0.05)$.

Fonte: Elaborado pelos autores.

O indicador Educação formal refere-se ao nível de escolarização do titular do sistema de produção, indo desde a ausência de educação formal até curso superior na área da atividade pecuária. Os resultados para este indicador foram bastante baixos e não superam os $20 \%$ de sustentabilidade para o indicador, o que revela que os produtores dos sistemas estudados têm, em média, o curso primário de educação formal (Figura 6).

Figura 6 - Indicadores do atributo Adaptabilidade (\%) dos sistemas de produção CN, $\mathrm{CN}+\mathrm{C}$ e $\mathrm{CN}+\mathrm{S}$ na região central do RS, em 2014

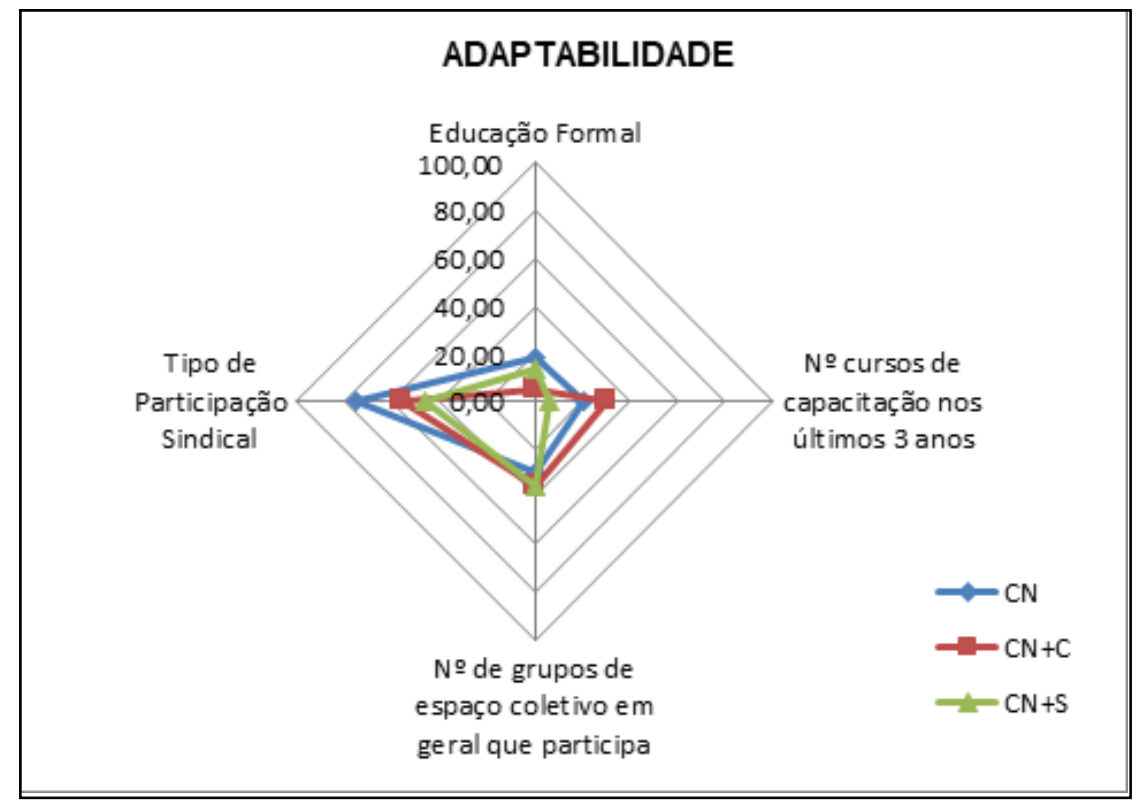

Fonte: Elaborado pelos autores.

O número de cursos de capacitação realizados nos últimos três anos, juntamente com o indicador Educação formal, é o de resultados mais baixos, destacando-se ambos como os pontos mais críticos deste atributo, em que os sistemas de produção apresen- 
taram resultados que superaram escassamente $30 \%$ de sustentabilidade. Duas razões podem ser consideradas: os cursos oferecidos não despertam o interesse ou os produtores não têm acesso a eles quando são ofertados. Devemos considerar, entretanto, os novos fluxos de informações através do rádio, TV, Internet e telefonia móvel, que permitem o acesso aos mais diversos conteúdos e que devem ser incluídos em futuras pesquisas como fontes de informação/formação.

Quanto ao indicador Número de espaços coletivos em geral de que participa, que apenas atingiu o valor máximo de $36,11 \%$ no sistema $\mathrm{CN}+\mathrm{C}$, cabe destacar que este indicador apresenta o maior valor de ponderação dentro do atributo Adaptabilidade. Quanto ao indicador de Participação sindical, este foi elaborado em uma escala que demonstra se existe participação e seu tipo. Por meio desta escala podemos identificar o produtor que não participa de sindicatos, aqueles que apenas utilizam o espaço e os produtores que participam efetivamente. Embora este tenha sido o indicador de melhores resultados dentro do atributo, devemos considerar que muito desta participação está diretamente ligado a serviços de saúde prestados pelo sindicato aos produtores, levando-os a responderem que participam do sindicato decorrente deste fato e não de uma participação sindical efetiva. Assim, quanto à participação dos produtores dos três sistemas em espaços coletivos e em sindicatos, os resultados vão ao encontro da característica individualista dos pecuaristas familiares, descrita por Ribeiro (2009) e Porto et al. (2010).

Analisando o atributo da sustentabilidade Equidade, de acordo com a Tabela 3, não existem diferenças significativas para as médias dos três sistemas de produção estudados. Ao analisarmos, no entanto, os indicadores que compõem o atributo, identificamos diferença significativa $(p<0,05)$ para um dos indicadores, conforme podemos observar na Tabela 7. Neste atributo os pesquisadores desenvolveram indicadores que retratam a forma como os recursos naturais utilizados estão resultando em benefícios aos sistemas de produção, considerando os custos que estão por trás de cada prática de manejo.

Tabela 7 - Médias ponderadas obtidas para os indicadores de Equidade (\%) dos sistemas de produção CN, CN+C e CN+S na região central do RS, em 2014

\begin{tabular}{lccc}
\hline Indicadores de equidade & $\mathbf{C N}$ & $\mathbf{C N + C}$ & $\mathbf{C N + S}$ \\
Água de qualidade, sombra e manejo & $13,71^{\mathrm{a}}$ & $12,83^{\mathrm{a}}$ & $10,77^{\mathrm{a}}$ \\
Resistência a parasitos & $20^{\mathrm{a}}$ & $16,89^{\mathrm{a}}$ & $19,69^{\mathrm{a}}$ \\
\% de CN melhorado no sistema & $18,85^{\mathrm{a}}$ & $23,73^{\mathrm{b}}$ & $23,52^{\mathrm{b}}$ \\
\% de pastagem cultivada no sistema & $18,89^{\mathrm{a}}$ & $17,87^{\mathrm{a}}$ & $14,57^{\mathrm{a}}$ \\
Escala de padronização do rebanho & $6,5^{\mathrm{a}}$ & $5,78^{\mathrm{a}}$ & $6,46^{\mathrm{a}}$ \\
\hline
\end{tabular}

Anova. Mesmo indicador com letras diferentes indica diferenças significativas entre os sistemas $(p<0.05)$.

Fonte: Elaborado pelos autores.

$\mathrm{O}$ índice de sustentabilidade para o atributo Equidade foi elaborado por meio de cinco indicadores com diferentes ponderações (Tabela 2). Os indicadores Água de qualidade, sombra e manejo e Escala de padronização do rebanho receberam ponderação de $14 \%$ dentro do atributo. Os demais indicadores receberam peso de $24 \%$ cada um. Embora o indicador \% de campo nativo no sistema apresente diferença estatística 
$(p<0,05)$ entre as médias dos sistemas e seja um dos indicadores com maior peso dentro do atributo Equidade, esta diferença não foi suficiente para resultar em diferenças significativas entre as médias de Equidade.

$\mathrm{Na}$ Figura 7 observamos os resultados dos indicadores de Equidade de forma integrada. Podemos identificar o indicador Escala de padronização do rebanho como o ponto mais deficiente dentro do atributo. Este indicador avaliou a padronização dos rebanhos bovinos e ovinos e considerou como índice máximo de sustentabilidade (100\%) os sistemas de produção que possuem rebanho padronizado em ambas as criações. Assim, apesar da utilização de todos os recursos naturais disponíveis ao sistema, não estão sendo suficientes para proporcionar a padronização do rebanho. Os resultados inferiores a $50 \%$ de sustentabilidade para todos os sistemas avaliados indicam que a produção animal continua a ser vista como reserva de capital por sua característica de produção de baixo risco, tal como citado anteriormente (VIANA; SILVEIRA, 2009; VIANA et al., 2012; NICOLOSO; SILVEIRA, 2013).

Figura 7 - Indicadores do atributo Equidade (\%) dos sistemas de produção CN, $\mathrm{CN}+\mathrm{C}$ e $\mathrm{CN}+\mathrm{S}$ na região central do RS, em 2014

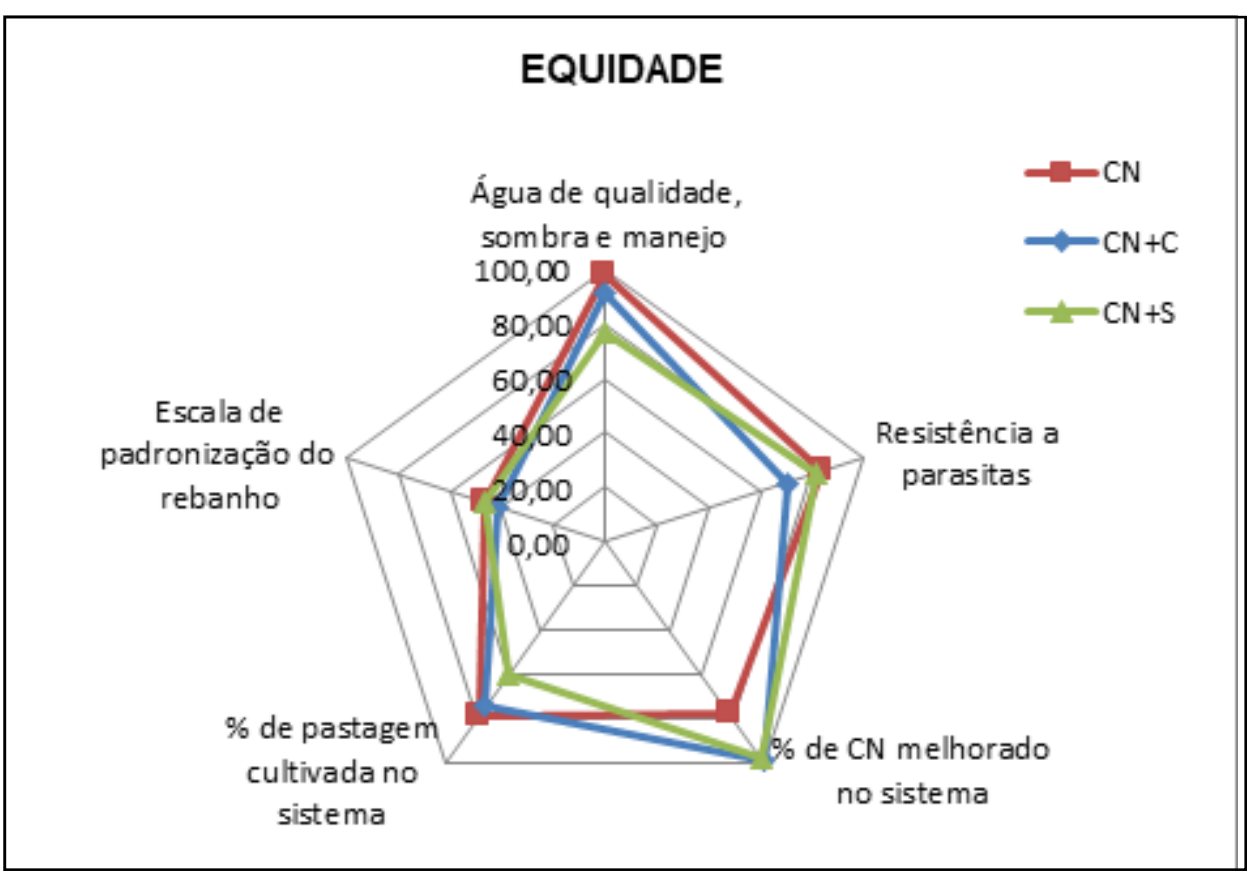

Fonte: Elaborado pelos autores.

Os resultados dos indicadores de manejo e bem-estar animal (água de qualidade, sombra e manejo; resistência a parasitas) indicam que estes aspectos estão sendo bem observados pelos produtores de todos os sistemas estudados, ou seja, que os recursos empregados nas alternativas de manejo estão resultando em benefícios ao sistema.

Quanto ao indicador \% de pastagens cultivadas no sistema, não houve diferenças significativas entre as médias dos sistemas de produção. Para o indicador \% de CN melhorado no sistema, o que se entende por mais sustentável são os sistemas que não necessitam utilizar deste recurso. Dessa forma, quando menor a proporção de áreas com pastagem natural melhorada em relação a SAU, mais sustentável é o sistema de produção para este indicador. $\mathrm{O}$ sistema de produção $\mathrm{CN}$ apresentou resultado inferior 
$(p<0,05)$ para este indicador quando comparado com os sistemas $\mathrm{CN}+\mathrm{C}$ e $\mathrm{CN}+\mathrm{S}$, que são iguais entre si. Este resultado, possivelmente, seja em decorrência de maior contribuição de pastagens cultivadas nos sistemas $\mathrm{CN}+\mathrm{C}$ e $\mathrm{CN}+\mathrm{S}$, o que possibilita que estes sistemas não necessitem recorrer ao melhoramento de pastos naturais para manter 0 aporte de nutrientes e oferta de forragem em período de inverno, quando ocorre o decréscimo quantitativo e qualitativo do campo natural no bioma Pampa.

Para o atributo Autossuficiência a Tabela 3 mostra que não houve diferenças significativas entre as médias dos sistemas de produção da pecuária familiar. Da mesma forma, para os indicadores que constituem este atributo, não foram encontradas diferenças significativas entre as médias dos sistemas (Tabela 8).

Tabela 8 - Médias ponderadas obtidas para os indicadores de Autossuficiência (\%) dos sistemas de produção CN, CN+C e CN+S na região central do RS, em 2014

\begin{tabular}{lccc}
\hline Indicadores de Autossuficiência & $\mathbf{C N}$ & $\mathbf{C N}+\mathbf{C}$ & $\mathbf{C N + S}$ \\
\% da superfície total como proprietário & $35,86^{\mathrm{a}}$ & $31,56^{\mathrm{a}}$ & $26,73^{\mathrm{a}}$ \\
\% da dívida total anual/receita bruta & $30,47^{\mathrm{a}}$ & $31,99^{\mathrm{a}}$ & $34,23^{\mathrm{a}}$ \\
\% da dieta em suplementação & $13,33^{\mathrm{a}}$ & $14,07^{\mathrm{a}}$ & $13,33^{\mathrm{a}}$ \\
\hline
\end{tabular}

Anova $(p<0.05)$.

Fonte: Elaborado pelos autores.

Os resultados integrados dos indicadores de Autossuficiência, apresentados na Figura 8, mostram que todos os sistemas atingiram índices de sustentabilidade superiores a $60 \%$ em todos os indicadores, sinalizando o potencial dos sistemas em se regularem e controlarem suas relações com o cenário exterior.

Figura 8 - Indicadores do atributo Autossuficiência (\%) dos sistemas de produção CN, $\mathrm{CN}+\mathrm{C}$ e CN+S na região central do RS, em 2014

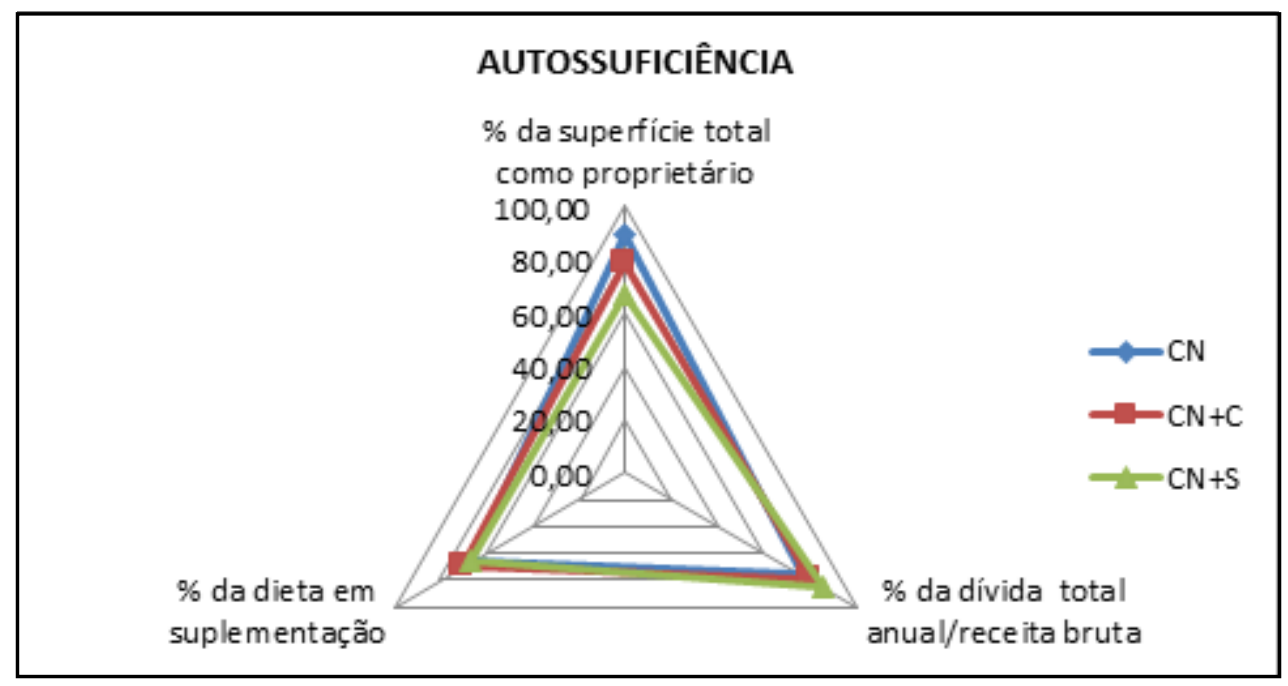

Fonte: Elaborado pelos autores.

O indicador \% da superfície total como proprietário demonstra a relação entre terras própria e terras em regime de arrendamento em que o sistema funciona. A propriedade da terra é um ponto importante, pois a área não própria, em arrendamento, representa uma incerteza no futuro do sistema. Embora o custo de implementos envol- 
vidos na atividade agrícola, acrescido do preço de venda da soja, estimulem o arrendamento de terras de vizinhos por parte dos produtores com a finalidade de produzir o grão, não foram detectadas diferenças significativas para este indicador.

O nível de endividamento do sistema de produção está representado pelo indicador \% da dívida total anual/receita bruta, ou seja, relaciona as dívidas a serem pagas no ano com a renda bruta. Níveis altos de endividamento, mesmo que a dívida seja feita com a finalidade de investimento, são preocupantes, pois comprometem o futuro da atividade na medida em que potencializam os riscos. Neste estudo, o valor mínimo de sustentabilidade encontrado para o indicador \% da dívida total anual/receita bruta foi de $75 \%$, indicando que o nível de endividamento dos sistemas de produção não é demasiadamente alto.

A \% da dieta em suplementação apresentou resultados acima de $65 \%$ de sustentabilidade para o indicador, e o que se pode observar por intermédio dos dados é que o uso da suplementação se dá em momentos estratégicos do ano e não é utilizado como um recurso habitual para os sistemas estudados.

\section{CONSIDERAÇÕES FINAIS}

Não foram encontradas diferenças significativas entre os três sistemas de produção estudados para os atributos de sustentabilidade propostos pelo método Mesmis, exceto para o atributo Produtividade. Para este atributo houve diferenças estatísticas entre os sistemas $\mathrm{CN}+\mathrm{C}$ e $\mathrm{CN}+\mathrm{S}$. Desta forma, o sistema $\mathrm{CN}+\mathrm{C}$ é mais sustentável que o sistema $\mathrm{CN}+\mathrm{S}$, considerando os parâmetros avaliados neste estudo.

Analisando os indicadores que compõem o atributo Produtividade, observa-se a rigorosidade avaliativa do indicador "Presença de diferentes cultivos" e sinaliza a razão de tal diferença. Este indicador penaliza enfaticamente a existência do cultivo da soja no sistema de produção, o qual, invariavelmente, recebeu $0 \%$ de sustentabilidade. Associados ao indicador Percentual de cultivos no sistema, estes resultados foram determinantes para a diferença. Desta forma, o rigor no entendimento do que é mais ou menos sustentável na ótica dos elaboradores dos indicadores influencia os resultados.

Por meio dos resultados obtidos para o atributo Estabilidade, identifica-se dificuldades nos três sistemas de produção em manterem sua capacidade produtiva ao longo do tempo. Os indicadores utilizados demonstram que estes sistemas possuem fragilidades, principalmente no que tange à quantidade de terra que será recebida por cada herdeiro em caso de sucessão ser capaz de garantir a sua manutenção na atividade. Entre os cinco atributos avaliados, o que representa o ponto mais crítico para os sistemas de produção analisados é a Adaptabilidade. Os indicadores para este atributo demonstram que os produtores de todos os sistemas de produção possuem, em média, baixo nível de educação formal, não realizaram cursos de capacitação para atividade seja por dificuldades de acesso, desinformação ou qualquer outra questão, e ainda, participam pouco em espaços coletivos, sejam comunitários ou sindicais. Segundo os resultados obtidos pelos critérios de diagnósticos e indicadores estabelecidos para o cálculo do atributo Adaptabilidade, os sistemas estudados, em caso de enfrentarem adversidades, neste momento teriam dificuldades em encontrar novo ponto de equilíbrio. 
Para o atributo Equidade os indicadores apresentam valores que elevam o valor final de sustentabilidade para este atributo em relação aos citados anteriormente. Considerando os cinco atributos estudados, os sistemas de produção em análise tiveram desempenho acima de $75 \%$ de sustentabilidade para Equidade, ressaltando como aspecto mais crítico dentro do atributo o indicador "Padronização do rebanho".

Os resultados dos três sistemas para o atributo Autossuficiência demonstram que a capacidade de autorregulação neste estudo está acima de $74 \%$, sendo este o valor mínimo de sustentabilidade obtido para Autossuficiência ( $\mathrm{CN}+\mathrm{S})$.

Os resultados revelam que o método Mesmis é adequado para avaliar a sustentabilidade dos diferentes sistemas de produção da pecuária de corte familiar tal como foi proposto neste artigo. Se considerarmos a sustentabilidade da pecuária familiar como sendo a capacidade das famílias de se manterem produzindo e vivendo de maneira digna, ao longo do tempo e em harmonia com o meio ambiente, pode-se afirmar que os indicadores vistos de forma isolada não têm valor. Quando, porém, comparados entre as famílias de um mesmo sistema ou os sistemas entre si, é uma importante ferramenta para escalonar graus de sustentabilidade e apontar oportunidades de intervenção para a extensão rural, no sentido de transformar e contribuir para a melhoria dos sistemas e, em consequência, da qualidade de vida das famílias assistidas.

Apesar de avaliar distintos aspectos dos sistemas de produção, diferenças significativas não foram encontradas, com exceção do atributo Produtividade. Isto nos sinaliza que, apesar de estarmos comparando sistemas de produção em que existe ou não a produção vegetal, estes sistemas, por terem como base a produção animal, desenvolvem práticas de manejo, produção e estratégias produtivas e mercadológicas semelhantes.

Outros fatores podem ter influenciado os resultados observados, tal como o número da amostra. Por se tratar de sistemas de produção heterogêneos, é possível que, ao analisarmos um número maior de sistemas de produção dentro de cada grupo, se encontrem maiores similaridades dentro de cada grupo e proporcionando a identificação de maiores diferenças entre os grupos. Cabe ressaltar que o método Mesmis tem previsto a possibilidade de inclusão, exclusão e adaptação dos indicadores ao propor a continuidade da análise de sustentabilidade por meio de novos ciclos, permitindo acompanhar a evolução dos sistemas estudados ao longo do tempo, bem como o efeito de intervenções nesses sistemas. Dessa forma, a revisão dos indicadores, novos ciclos de avaliação, bem como aumentar o tamanho da amostra estudada podem nos revelar resultados ainda não apreciados e importantes para o entendimento desses sistemas de produção, seus processos e dinâmicas em questão.

\section{AGRADECIMENTOS}

Os autores agradecem a colaboração dos técnicos municipais da Emater-RS, sem os quais este trabalho não poderia ter sido realizado: Abel Gonçalves Dias, Dario Afonso Salbego Bem, Edison França Vieira, Eduardo Blaya Figueiró, Fernando Luis Hillebrand, Flávia Dalmolin, Flávio Jesus Ferreira Rodrigues, Flávio Júnior Rumpel Brum, Guilherme Godoy dos Santos, João Francisco Comiz, Lilian Varini Ceolin, Marcelo Gomes Steiner, Mônica Pivetta Foldenauer, Regina Helena Santarém Hernandes, Ricardo Lopes Machado, Rodrigo da Rosa Becker, Victor Alvino Keller Cassol, Vitor Luis Gomes Rocha e Wladimir Bolzan Cadó. 


\section{REFERÊNCIAS}

ALTIERI, M. Agroecologia: a dinâmica produtiva da agricultura sustentável. 2. ed. Porto Alegre: Ed. Universidade, 2000.

CAPORAL, F. R.; COSTABEBER, J. A. Análise multidimensional da sustentabilidade: uma proposta metodológica a partir da Agroecologia. Agroecol. e Desenv. Rur. Sustent., Porto Alegre, RS, v. 3, n. 3, p. 70-85, 2002.

CARVALHO, H. M. Padrões de sustentabilidade: uma medida para o desenvolvimento sustentável. Curitiba, 1993. (Mimeo). 26 p.

CAVALCANTI, C. Sustentabilidade da economia: paradigmas alternativos da realização econômica. In: CAVALCANTI, C. (Org.). Desenvolvimento e natureza: estudo para uma sociedade sustentável. São Paulo: Cortez; Recife, PE: Fundação Joaquim Nabuco, 1998.

GALVÁN-MIYOSHI, Y.; MASERA, O.; LÓPEZ-RIDAURA, S. Las evaluaciones de sustentabilidad. In: ASTIER, M.; MASERA, O.; GALVÁN-MIYOSHI, Y. (Org.). Evaluación de Sustentabilidad. Un enfoque dinámico y multidimensional. Espanha: Seae; Ciga; Ecosur; Cieco; Unam; Gira; Mundiprensa; Fundación Instituto de Agricultura Ecológica y Sustentable, 2008.

LÓPEZ-RIDAURA, S.; MASERA, O.; ASTIER, M. Evaluating the sustainability of complex socio-environmental systems: the MESMIS framework. Ecological Indicators, 2, p. 135-148, 2002.

MASERA, O. ¿Qué tan sustentable es el manejo de los recursos naturales? In: PAREDES, O. L.; ORIHUELA, $\mathrm{S}$. (Coord.). Aportaciones científicas y humanística mexicanas en el siglo XXI. México: FCE; Academia Mexicana de Ciencias, 2008.

MASERA, O.; ASTIER, M; LÓPEZ-RIDAURA, S. Sustentabilidad y manejo de recursos naturales. El marco de evaluación Mesmis. México: Gira Mundi Prensa, 1999.

MEUL, M. et al. Motifs: a monitoring tool for integrated farm sustainability. Agron. Sustain. Dev., 28, p. 321-332, 2008.

MINISTÉRIO DO MEIO AMBIENTE (MMA). Pampa: fôlder pampa - conhecimentos e descobertas. 2014. Disponível em: <http://www.mma.gov.br/biomas/pampa/>. Acesso em: 25 mar. 2016.

NICOLOSO, C. S.; SILVEIRA, V. C. P. Rastreabilidade bovina: histórico e reflexões sobre a situação brasileira. Rama: Revista em Agronegócio e Meio Ambiente, v. 6, p. 79-97, 2013.

PIZZATO, F. Pampa gaúcho: causas e consequências do expressivo aumento das áreas de soja. 2013. 105p. Dissertação (Mestrado) - GEO-UFRGS, 2013.

PORTO, R. G. et al. Pecuária familiar: a emergência de uma categoria social no Sul do Brasil. Revista Economia e Sociologia Rural, Brasília, v. 48, n. 2, 2010.

RIBEIRO, C. M. Estudo do modo de vida dos pecuaristas familiares da Região da Campanha do Rio Grande do Sul. 2009. 300p. Tese (Doutorado) - PPGDR-UFRGS, 2009.

RIO GRANDE DO SUL. Decreto no 48.316, de 31 de agosto de 2011. Regulamenta o Programa Estadual de Desenvolvimento da Pecuária de Corte Familiar - PECFAM, instituído pela lei no 13.515, de 13 de setembro de 2010, e dá outras providências. Diário Oficial [do Estado do Rio Grande do Sul], Porto Alegre, n. 170, 4 p., 10 set. 2011.

SCHOLOTTFELDT, C. B. A importância econômica e social dos pequenos e médios agricultores para a política agrícola no Brasil. Brasília: Embrapa - MA, 1983. (Mimeo).

SEVERO, C. M.; MIGUEL, L. A. A sustentabilidade dos sistemas de produção de bovinocultura de corte do Estado do Rio Grande do Sul. Redes, Universidade de Santa Cruz do Sul (Unisc), Santa Cruz do Sul: Ed. da Unisc, vol. 11, n. 3, p. 213-234, set./ dez. 2006.

SILVEIRA, V. C. P.; GONZÁLEZ, J. A.; FONSECA, E. L. Land use changes after the period commodities rising price in the Rio Grande do Sul State, Brazil. Ciência Rural, v. 47, n. 4, 2017.

SPEELMAN, E. N. et al. Ten years of Sustainability Evaluation using the MESMIS framework: Lessons learned from its application in 28 Latin American case studies. International Journal of Sustainable Development and World Ecology, n. 14, p. 345-361, 2007.

VIANA, J. G. A. et al. Governance and transaction costs in the sheep production chain in Rio Grande do Sul, Brazil. African Journal of Business Management, v. 6, p. 4.376-4.385, 2012.

VIANA, J. G. A.; SILVEIRA, V. C. P. Análise econômica da ovinocultura: estudo de caso na metade sul do Rio Grande do Sul, Brasil. Ciência Rural, v. 39, p. 1.176-1.181, 2009. 